\title{
The Adventure of Hospitalization
}

\author{
Freya Ruijs \\ Delft University of Technology
}

\section{The Adventure of Hospitalization}

The adventurer's kit is a small suitcase that was designed for children (aged 3 to 6) who are hospitalized for a surgical procedure. The suitcase contains several playful items: a passport, a flag, a storybook and four sets of toys, each set representing a fictional character: Pip, Sophie, Charley, and Damian (Figure 1). The design intends to stimulate and enable the child to perceive the hospitalization as an adventure. This should provide the children with a protective frame when encountering stressful or scary situations. During hospitalization, the experience of negative emotions is inevitable, but with the protective frame, these emotions can become part of an overall adventure narration and thus be less stressful.

The kit is used during all stages of hospitalization (see Figure 2 for an impression of usage). The children receive and start using the kit some time before their actual hospitalization. In the preparation period, the children and caretakers have a meeting with the specialist, in which the child will receive his or her own adventurer's kit. This helps the specialist to open up a conversation between parents, children, brothers, sisters and other peers. In addition, in the period between this meeting and the hospitalization, the kit will help the child in preparing for a stay at the hospital. With parental guidance, the child makes and decorates a personal flag and reads the storybook. The story tells about a family with four children: each with a different playing style.

The suitcase contains sets of toys related to each of these four characters, each set representing a different coping strategy. Pip likes to act out things. He has four animal friends who represent different emotions. He can use them as a shield and to show how he feels to his caretakers. Charley likes to explore things to understand them. He has a set of colored safety glasses that enable him to explore the hospital. Sophie likes active play and learning new skills. She brings an active game that can be played in the bed and a roadmap with stickers to track her experiences. Lastly, Damian is a

Freya Ruijs, Department of Industrial Design, Delft University of Technology.

Correspondence concerning this article should be addressed to Freya Ruijs, JAM Visueel denken, Plantage Middenlaan 62, 1018DH, Amsterdam, The Netherlands E-mail: freya@jamvisualthinking.com

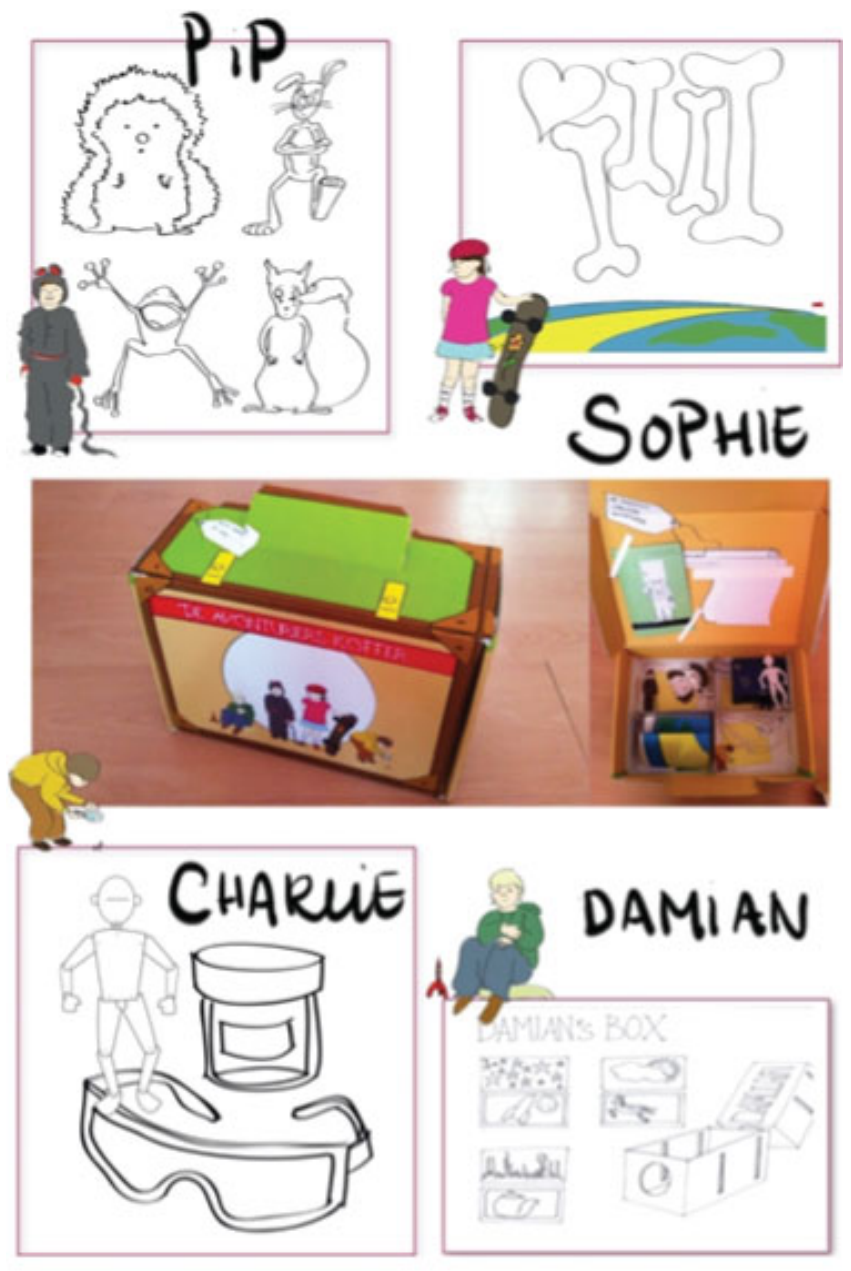

Figure 1. Adventurer's kit.

very creative and loves stories. He has a dreamcatcher, a box in which he can collect his favorite dreams to bring to the hospital. When arriving in the hospital, the child receives a check-in stamp in his or her personal passport. The stamps (both check-in and check-out) mark the boundaries of the hospitalization and add to the experience of the adventure. At the ward, the child (with the help of the childcare worker) attaches the flag to his or her bed - explicitly claiming the bed, making it a safe base within the new and alien-feeling hospital environment. When going to the hospital, the kit will already be familiar, bringing a safe element to an un- 


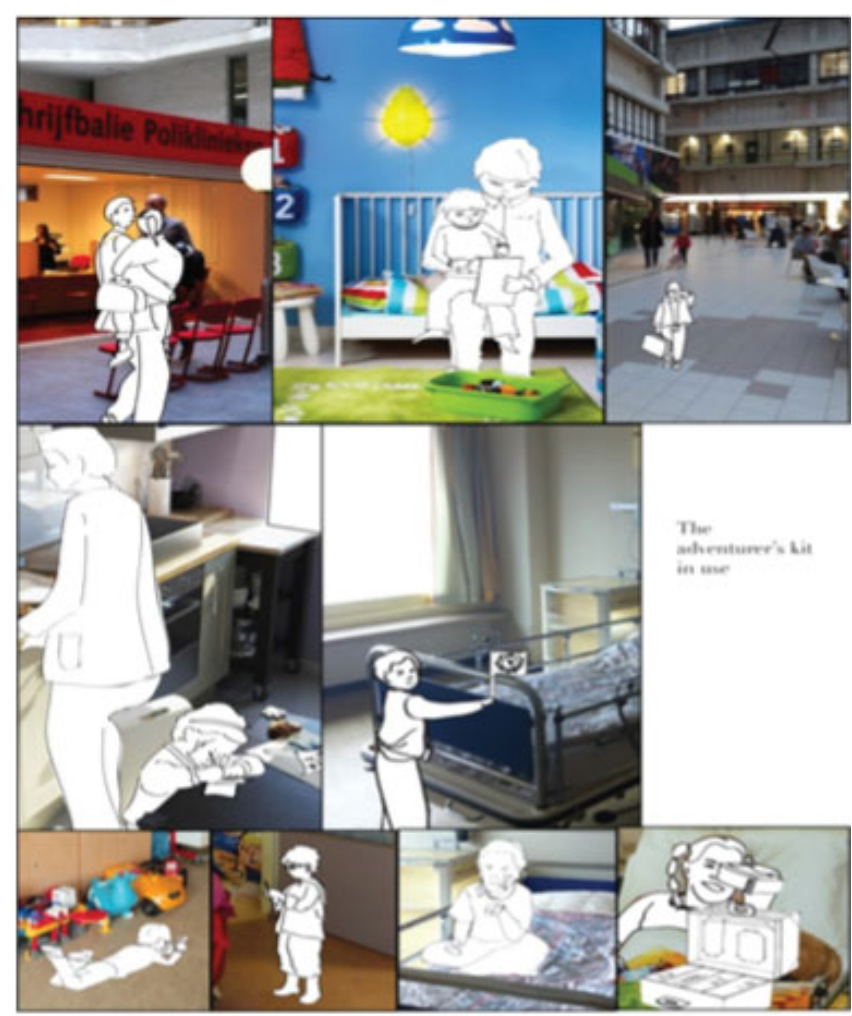

Figure 2. The adventurer's kit in use.

familiar and (sometimes) scary environment. Without making the choice explicit, the children can use the toys that suit them best, providing them with a fitting coping strategy and protective frame.

\section{Design challenge}

The Adventure of a Hospitalization was the author's graduation project of the Design for Interaction master's program at Delft University of Technology, The Netherlands. The project was completed at the Emma Children's Hospital, which is part of the Academic Medical Centre in Amsterdam and one of five specialist children's hospitals in The Netherlands. Within the Emma Children's hospital about 4,700 children are hospitalized every year. Since hospitalization can be a stressful experience, the children and their parents are guided by specialized childcare workers. Unlike the medical staff of the hospital, the childcare workers focus specifically on the emotional well-being of the children and their family. Because childcare workers are working under considerable time pressure, the aim of the current project was to design a tool that supports them in their intention to provide excellent care with the limited time available per patient.

Hospitalized children can experience strong unpleasant emotions in response to their medical condition, to the hospital context, and to the medical procedures. The main chal- lenge in the current project was that these negative emotions were given and that their causes could not be taken away by design interventions. So rather than preventing negative emotions, the design should somehow support the children in dealing with these emotions. Reversal theory proposes that negative emotions are not necessarily unpleasant, depending on whether or not the individual has a protective frame (Apter, 1989). The designer therefore decided to explore if it is possible to reverse these strong given negative emotions into a more positive experience by helping children to create a protective frame.

\section{Project approach}

In order to gain insight in the user and the context of use, the designer spent a full week in the hospital, observing and interviewing children and their parents. In addition, several (group) interview sessions with child caretakers were conducted and a literature study was done to gain insights in child emotions and development. With the resulting insights, the four child-personas were created, representing the diversity of children in terms of needs, emotional development, playing style, dominant emotions, and potential protective frame. These personas were used as an inspiration for creating ideas and concepts. Several were prototyped and tested, and the resulting insights were used to create the adventurers kit. Ruijs (2011) reported a detailed description of the project including the various research steps and design iterations.

\section{Insights and design implications}

A key insight drawn from the research was that within the diversity of children, families, medical conditions, and so on, all hospitalized children had one factor in common: play. In the hospital environment, play is essential because it supports relaxation and emotional processing. It was therefore decided that play would be the starting point for the design. Because play requires a safe environment, the design challenge was to create this safety without changing the actual situation or environment (which was a given in this design project). The design idea was to use adventure as a play metaphor to stimulate a general protective frame to transform the overall experience and to stimulate additional individual protective frames that would make play possible in the hospital environment. To deal with the diversity of children, the typology with four playing styles that was proposed by Gielen (2010, based on Kolb, 1984) was used to create four personas with different protective frames (i.e., confidence, detachment, and safety-zone frames, see Apter, 1989). For each persona, toys were developed that targeted the particular coping strategy and playing style (an active game, animal friends, a set of colored safety-glasses, and a dreamcatcher). The first persona, the Achiever (enjoys challenge and physically active play: Sophie), represents children who 
like to treat new and unfamiliar situations as positive challenges. The active game was designed to provide them with a confidence frame by offering challenges that fit with their skills, giving them the confidence that they can deal with encountered obstacles. The second persona, the Actor (enjoys fantasy and physically active play; Pip), represents children who like to dive into the experience of new and unknown situations. The animal friends intend to provide them with a confidence frame by enabling them to use the puppets to act out their experiences in a language and pace that fits their skills. The third persona, the Thinker (enjoys challenge and sensory experiences; Charley) represents children who are curious and like to take an explorative attitude. The colored safety glasses provide them with a safety-zone frame by creating a literal and metaphorical distance between them and the situations that they encounter. The fourth persona, the Dreamer (enjoys fantasy and sensory experiences; Damian) represents children who like to keep distance and fantasize an imaginative version of reality. The dream catcher intends to provide them with a detachment frame, stimulating them to create their personal distanced version of their hospital experiences.

\section{Discussion}

Reversal theory proved to be a crucial resource for this project. Clearly, the unpleasant experiences of hospitalized children could not be prevented or made to go away with design intervention. Even so, reversal theory indicated that design can be relevant if it supports children in creating and maintaining a mental protective frame that helps them in dealing with the situation. Rather than solving the experiential problem, the adventurer's kit helps the children in building their resilience to face this problem, by themselves and with their family. Although inspiring, it was not easy to use protective frames as design themes. Reversal theory offers some descriptive guidelines, but these were found to be too abstract to be of direct use in a design context. Once they were linked to and combined with the personas, these guidelines became more tangible. In the context of the personas, the protective frame theory proved its value to the designer. It appeared that when designing for protective frames, the chance of success increases when the designer has rich insights in and information about the user and design context at hand. The more detailed the tools were (e.g., the personas), the easier it became to translate the abstract boundaries of the coping strategies to a realistic design concept. Note that it was found that a lot of the design was based on the designer's personal interpretation and combination of insights. Nonetheless, the outcomes can be seen as an exploration of how design can contribute to transforming negative emotions into positive experiences and serve as an inspiration to designers by showcasing how reversal theory can be used to design.

\section{References}

Apter, M.J. (1989). Reversal theory; the dynamics of motivation emotion and personality. Oxford: Oneworld Publications.

Gielen, M.A. (2010). Essential concepts in toy design education: aimlessness, empathy and play value. International Journal of Arts and Technology, 3(1), 4-16.

Kolb, D.A.(1984). Experiential learning: Experience as the source of learning and development. New Jersey: Prentice Hall.

Ruijs, F. (2011). The adventure of a hospitalization: designing a tool for the childcare workers at the Emma Children's Hospital in Amsterdam. Unpublished master thesis, Delft University of Technology, Delft, The Netherlands. 